\title{
A Defense of William James on Moral Truth
}

\author{
Tiantian Zhang \\ School of Philosophy, Beijing Normal University, Beijing, China \\ Email: zhangtt9009@163.com
}

How to cite this paper: Zhang, T. T. (2021). A Defense of William James on Moral Truth. Open Journal of Social Sciences, 9, 1-13.

https://doi.org/10.4236/jss.2021.96001

Received: April 7, 2021

Accepted: June 4, 2021

Published: June 7, 2021

Copyright (c) 2021 by author(s) and Scientific Research Publishing Inc. This work is licensed under the Creative Commons Attribution International License (CC BY 4.0).

http://creativecommons.org/licenses/by/4.0/

\begin{abstract}
Like his theory of truth, William James's view on moral truth is also confusing. On the one hand, he declared that "there is a truth to be ascertained" (James, 1979) in ethics and the best act is the one that makes for the best whole, in the sense of awakening the least sum of dissatisfaction. However, on the other hand, he argued that there is no final truth in ethics and a stable and systematic moral world cannot exist unless there is a divine thinker. For many scholars, these two different statements appearing seem conflict to each other. However, to my knowledge, the alleged contradiction is a misunderstanding of James's thought. In this essay, I am going to clarify James's view on moral truth from a pragmatic perspective and show that James's view on moral truth is based on his understanding of pragmatic truth and his pluralistic world view, a better approach to interpreting his view of moral truth is to highlight his key points of pragmatism and pluralism.
\end{abstract}

\section{Keywords}

William James, Moral Truth, Moral Inquiry, Pragmatism

\section{Introduction}

As one of the representatives of pragmatism, Williams James was well-known as a scientist, a psychologist, a religious believer and a public speaker; however, few scholars treated him as a moral philosopher. One reason is that James did spend volume time and energy in psychology, religion and relevant themes, while another important reason is that he never developed a theory to clarify his position on ethics even if his analysis of ethical questions is significant and instructive. Thus it is difficult to grasp his total moral thoughts. Of course, some excellent philosophers and thinkers have done much work on James's moral philosophy, like Bernard P. Brennan, Sergio Franzese, as well as Sarin Marchetti; they all tried their best to outline James's moral philosophy and make their interpretation convincing and inspiring, while there are also some problems left for us to 
discuss.

"The Moral Philosopher and the Moral Life" (hereafter MPML), one of the essays in James's work The Will to Believe and Other Essays in Popular Philos$o p h y$, is his most important ethical working and the only one that James discussed moral issues intensively. It is an incredibly rich essay that not only shows James's views on ethics, even if confusing, but also offers his general approach to analysis of ethical issues. I believe that it should be a good start to approaching James's moral thinking from this essay. Indeed, it will be argued that the paper is occasionally frustrating because James let his discussion about ethics open and some inconsistency appears in the essay, especially his different statements about moral truth. However, I will here claim that there is no inconformity on James's view of moral truth. The so-called inconsistency in fact is a kind of inappropriate understanding of James's moral thought, and the different statements about moral truth exactly show James's moral position if we read it in the context of James's overall philosophical thinking rather than limiting to his moral thinking. When James said that "there is a truth to be ascertained" (James, 1979), many scholars take for granted that James believes that there is a moral truth in ethics and an everlasting criterion on goodness is waiting to be discovered. We can oppugn this reading easily by quoting James's words that "The main purpose of this paper is to show that there is no such thing possible as an ethical philosophy dogmatically made up in advance" (James, 1979). Obviously, for James, "a truth to be ascertained" does not equal a truth to be discovered which is made up dogmatically in advance. What he expressed here is that as a moral philosopher, unlike a skeptic, believing a possibility of finding the final truth in ethics is a promise to make our hard working sensible, and a pre-assumption for us to understand and explain our moral experiences. Following this sentence, James added that "that truth cannot be a self-proclaiming set of laws, or an abstract 'moral reason', but can only exist in act, or in the shape of an opinion held by some thinker really to be found" (James, 1979). Proceeding in this way, it is easier to understand that his another seemed oddly statement, namely, "there can be no final truth in ethics any more than in physics, until the last man has had his experience and said his say" (James, 1979). Since moral truth the empirical result of moral inquiry, unless we explore all of the moral experience, there is no way to gain the final truth. Here, James uses the word "truth" in a pragmatic way, we are possible to gain the moral truth but not in an absolute way. The moral truth, just like some truths in epistemology, is the fruits of scientific observation and experiments, will change with the environment, social culture, experiences as well as other factors. It should be noted that James did not subscribe moral relativism or supported the idea that moral truth is relative to society or culture, he just tried to emphasize that we need to prepare to modify our truth (knowledge) when the experiences make their requests, after all, truth is the consequence of reflection of experiences. James refused any kind of absolute truth or final truth. About how to understand James's statements on moral truth is my goal of this paper, and I will attempt to show how James's view on moral 
truth fits in with his pragmatism and his overall philosophy.

\section{The Role of Moral Truth}

For James, pragmatism, as a philosophical method, its main function is "making our ideas clear", as it was primarily formulated by Charles Peirce in 1870s, although he did not use the word "pragmatism". The application of this method is by observing the situation in which one certain idea, concept, theory as well as problem embodied and then tracing out the actual and potential differences made by them. Therefore, to figure out his view on moral truth, coming back to the source of the statement with the understanding of his entire philosophy would be an efficient way. In MPML, according to my interpretation, James discusses moral truth in two ways.

\subsection{Moral Truth as Indispensable Hypothesis}

In the first section of MPML, James asked us "what is the position of him who seeks an ethical philosophy?" (James, 1979) It is not a question with little importance since its answer directly determines what we will do next. As James has made clear, moral inquirers and would-be moral philosophers, namely, who seeks an ethical philosophy, cannot be a moral skeptic. Because the moral skeptic would threaten the one who is willing to study moral philosophy at the outset. A moral skeptic is the one who holds the idea that there is no moral truth, thus he rejects the responsibility to the community which is contained in his identity as a scholar. He would like to close his eyes when faced with chaos moral orders since he believes that it is a waste of time and energy doing moral inquiry and no truth exists in ethical realm. Conversely, once we stand in the place of moral inquirers or would-be philosophers, it has shown that our target is to find the moral truth and we hold a strong belief that "there is a truth to be ascertained" (James, 1979). We admit our identity as moral inquirers so we believe strongly that "truth exists in ethical realm", and then we try our best to justify our faith. Here, this statement of moral truth often is treated as the hypothesis that, for James, authentic proposition about the goodness and moral judgement already exists before our inquiry, and our task is to discover it. Obviously, it is wrong. In fact, for James, such a statement mere is an indispensable hypothesis for our moral inquiry, as he put at the beginning of MPML, there are some hypotheses "which we now make while waiting, and the acts to which they prompt us, are among the indispensable conditions which determine what that 'say' shall be" (James, 1979).

As a moral explorer or moral philosopher of future, our identity requires some kind of hypothesis which we make before taking action and will determine what we shall do. Such a hypothesis is inherent in our role as a moral inquirer, then is indispensable conditions for our act and indicates the orientation of our conducts. Here, in the field of ethical inquiry, the indispensable assumption is that there is a moral truth or a system of moral truth to be ascertained. With this 
assumption, we begin our moral inquiry and believe what we do is valuable. To the contrary, if there is no possibility of the existence of moral truth, it is more possible that we tend to give up any moral inquiry since we are rational human beings. Note that, in this regard, instead of focusing on the content of moral truth, we merely treat it as a working hypothesis which enables our moral inquiry possible and meaningful. Namely, we treat moral truth abstractly and prior to experience, but not transcendental.

\subsection{Moral Truth as Fruit of Moral Inquiry}

Another form of moral truth which discussed deeply and intensively in MPML is the moral truth as fruit of moral inquiry. Here, it is necessary to clarify that James uses the notion of moral truth as fruit of moral inquiry in two senses without clear distinctions. One sense he attached to the notion comes into play when moral explorers who would be a moral philosophy, like James himself, begin to moral inquiry; the other sense of "moral truth" used by the moralist who is not a "judicial investigator and become an advocate for some limited element" (James, 1979). It is an important but often overlooked distinction between moral inquirers and moralists. In the first sense, for moral explorer like James, moral truth is the result of moral inquiry, but not keeping unchanged forever. For them, moral truth is provisional and open to test and modify with the emerging of new moral experiences. Until the moment when the last man has had his say, there will never be the final moral truth, and hence that our real situation will always be one in which moral improvement is possible and required. While for moralist, they hold a strong belief that the moral relations among things will "weave them into the unity of a stable system, and make of the world what one may call a genuine universe from the ethical point of" (James, 1979). The moralist insists that, by moral inquiry, in a way of sometimes empirical or sometimes abstract and dogmatic, we are capable of finding the everlasting principle something like the natural law in our moral life, and then we are allowed to stop our exploration. In this context, the moral truth which is held by moralist is the final truth in an absolute way in ethical realm. Thus, in the eyes of moralist, the moral truth is a symbol which means that we have achieved our goals of inquiry and grasp the core of moral experiences so we can stop here. Apparently, James is an advocator of the moral truth of impartial moral inquirers rather than moralists.

Here, I want to remark that the moral truth, as the fruit of moral inquiry, has its content. Generally speaking, it is the reflection of our moral practices and phenomena includes a series of moral principles or propositions, usually is a system of tidy philosophical theories which plays a vital role in our moral life. On the one hand, it concerns the knowledge about morality which tells us what is good and evil as well as why we proclaim something is good so that we can know our moral phenomenon and experience better. On the other hand, it is helpful to address moral conflicts since it formulates a criterion for us to access the amount of values of acts and ideas. In virtue of this fact, we can behave mo- 
rally and live a moral life with the guidance of moral truth. Notely, in this sense, we treated moral truth empirically and it is the truth which is constructed in the process of moral inquiry. We use it for moral judgment and moral reasoning. Still, it is necessary to remind the readers that what James is telling us is that, while it is true that we will never reach the final moral truth in an absolute sense, but we are still allowed to have our temporary truths works well and keep going the pursuit of final moral truth.

\section{Ascertain Moral Truth and the Practical Difficulties}

As I have made clear, for James, once we stand in the position of moral inquirer, the most significant task faced with us is to ascertain the moral truth (quoting James's words), and this is what has been done by moralists for thousands of years. In the history of moral philosophy, a widely accepted and adopted method to ascertain moral truth is to find the common essence which is contained in all the goods, namely, what makes it being good for us. Thus, then we can rank the diverse goods according to the amount of this common essence and make an ethical republic. However, the reality is that different philosophers obtain different theories about the essence of good in this way, and to make things worse, these theories all can explain parts of our moral experiences from a certain perspective but are not sufficient to clarify all of them, like Kant's deontology and Bentham's utilitarianism. Deontologists believe that one act or conduct is good as long as it obeys the moral law no matter its consequence or result, this principle justifies all the situations in which one tries to do something with a morally good motivation. Yet, merely good intention is not sufficient for morally good activities especially when the agent, to some extent, is ignorant. Likewise, one endorsing utilitarianism attributes the goodness of action to its result, he puts the consequences of actions at the top without considering the motivation that drove the action. Just as we are not allowed to say one who tried to kill another but failed is innocent. It is no doubt that these moral theories do make our moral judgement simple and efficient, but they all fail to achieve the universality declared all the time because we can always find some exceptions which can justify the shortcomings of these theories.

Not surprisingly, James had been aware of the deficiencies of such moral theories and we can tell from that his fruitful analysis in MPML. In this essay, James divided ethics into three questions: psychological question (asking for the historical origin of moral ideas and judgments), the metaphysical question (exploring the very meaning of the words), and the casuistic question (studying the measure of the various goods and ills), respectively (James, 1979). Here, James was accused not doing exactly what he said he will do since he did not answer these three questions directly. However, in my estimate, his analyses about ethics provide us (directly or indirectly) with rich resources to understand the failure of traditional moral theories as well as the direction of how to ascertain moral truth and its practical difficulties. I will explore in more detail in the following 
parts.

First of all, in speaking of the word "truth", as we generally used in the field of Epistemology, it means "a standard which outside of the thinker and he must conform" (James, 1979: p. 146). It has three important characters. The first one is that it must be universal, which means that it is available to all the cases, with no exception. Then accompanied by the universality, it must be objective. In other words, it must get rid of subjectivity. If something is true according to this standard, it must be true for you, for me, and for everyone. Thus, an immediate corollary is that it is of authority which means it has the power to force everyone to conform, because if we violate the truth, our practices are usually hindered. Naturally, we assume that the moral truth should also have such characters for it is truth. It is supposed to be universal, objective and authoritative. It should be utilized to compare all of acts which contain goodness and has the equal objectivity and authority for everyone. Moreover, it has the right to require us to obey otherwise we will pay the price.

Unfortunately, after exploration for thousands of years, the moral truth with such features has not been found yet. Or bluntly stated, for James, it would never be discovered if we insist on the traditional assumption of truth. Under the discussion of psychology question, by contrasting Intuitionism and Evolutionism, James delivered us a message: our moral perceptions are very complicated and mysterious to some degree. A great number of our moral perceptions are kind of brain-born preferences, relating with secondary affections and impulses, even to some purely inward forces. This means that the moral element in human nature is not any single quality, like pleasure or pain, rather a group of quality. Therefore, any attempt to induce our moral value in one single absolute principles is doomed to fail. To put it another way, there is no pure essence of good. To this, in the section of metaphysical question, after investigating the origin of goods, James added that moral properties, unlike natural properties, are not pure physical facts but reside in our sensitivity and cannot exist without subjective support. Moral terms "can have no application or relevancy in a world in which no sentient life exists" (James, 1979). If goodness, badness, and obligation really exist, they must be realized somewhere by someone. In virtue of this fact, we can conclude that it is impossible to exclude subjective factors of moral propositions since goodness itself is based on our subjectivity which is closely related to preferences and interests. When comes to casuistic question, James inculcated the idea again that it is impossible to find the impartial test of goodness into us. As mentioned above, the truth of moral propositions and judgements depends on our subjective support. In other words, moral truth "cannot be a self-proclaiming set of laws, or an abstract 'moral reason,' but can only exist in act, or in the shape of an opinion held by some thinker" (James, 1979). When we try to seek such a universal principle, an inevitable result is that the essence of good is to satisfy demands. However, "the elementary forces in ethics are probably as plural as those of physics are" (James, 1979). In the name of demands, there are a lot of 
things, including all kinds of categories, material as well as spiritual. The only thing in common among them is that they are all characterized by claiming by someone. Namely, the failure of traditional moral theories is not because that they are theories, it is just because that they all try to simply reduce moral values into one absolute element or principle, ignoring the richness and complexity of moral experiences. Furthermore, James never leaves us the impression that we are able to assess all the goods or demands. Actually, he warned us that considering the uniqueness of culture, history as well as personalities of moral agent, facing two subjects with the equal legitimacy, an inevitable upshot is that our judgments concerning the value of acts, once dealing with the significance of acts of alien lives, our judgement is becoming stupidity and injustice, more or less (James, 1983). In the final analysis, from James's discussion about ethics, moral properties cannot exist without moral perception, there is no common essence of good by which one might compare all acts and moral judgement and reasoning cannot be independent on subjective factors. In a word, revisiting the first sentence of this paragraph, we cannot ascertain the moral truth if we still hold the traditional assumption of truth.

Here, at first glance, it seems that James made himself into a kind of inconsistency: on the one hand, with the belief that there is a moral truth to be ascertained, James began his exploration with us and pointed out clearly that the common thing of good is to meet demand, and "the best act is the act which makes for the best whole, in the sense of awakening the least sum of dissatisfaction" (James, 1979) (hereafter the best whole principle) on which we are permitted to build our moral theory; while on the other hand, his analysis tries to prove that such moral truth is no possibility to be discovered given the nature of moral experiences. And "the stable and systematic moral universe for which the ethical philosopher asks is fully possible only in a world where there is a divine thinker with all-enveloping demands" (James, 1979). However, if we pay attention to the context of James's statement, as well as to his view on truth in pragmatism, we can appreciate that the statements on moral truth exactly presents James's moral attitude. The key to dissipating the suspicion of inconsistency is to figure out James's overall intent and the way in which we read it.

With no doubt, if following the traditional moral inquiry as well the common sense of truth, James's ideas on the essence of good as well as the best whole principle are plausible. These ideas have answered the classical moral philosophical questions: what is it that constitutes moral value? What is the test for our moral order? The answer for the first question is the satisfaction of demands, the second one is the best whole. However, that is not to say, we find out the moral truth and can develop a moral system, but to say that, proceeding the work of traditional moral philosophers, the moral truth that we are permitted to discovered is only James's conclusion. And evidently, such idea does not fit in the criterion of truth which hold by moralists. Here, what James try to emphasize is that if we regard moral truth, in a traditional epistemological way, as one 
thing that outside of the agent and is absolutely universal, objective as well as necessary, we are doomed to fail to find it in ethical realm, because the pre-assumption of truth, including moral truth has been wrong from the very outset. That is to say, the articulation of truth in traditional way missed the key point of truth. In James's term, by defining truth as universal, objective and absolute, it ignores the most important thing that what makes it true for us? What do we really mean when we say that one certain idea is true? For James, truth is never a standard independent of the thinker or imposed on our experiences from above. It is a kind of quality of some ideas, which is closely related to our preference, interests and responsibilities, and its most important function is to help us deal with experiences efficiently. This is the core idea of his pragmatist theory of truth. Although given the chronology, it would be too much to say that James analyzed moral truth in terms of his pragmatic theory of truth, the approach which he used to clarify the moral property and moral truth is pragmatic. From the analysis of psychological question to metaphysical question again to casuistic question, James investigated the origin of morality, the condition of usage of moral words and the differences that made by the moral principles. It is resonant with the way that he used to analyse the pragmatist truth. Hence, it is viable to understand his view on moral truth by referring his view on pragmatist theory of truth.

\section{An Alternative Way of Understanding Moral Truth}

James's interpretation of truth in Pragmatism is groundbreaking and insightful, as well as challenging. However, due to the limitation of space, I am not allowed to elaborate it in much detail here, which is off the target of the purpose of this article. Therefore, I will try my best to present the core of James's view of truth as briefly as I can. First of all, as a pragmatist, James never treats truth from an objective and external perspective. He did not deny that the human interest in knowing for the sake of knowing, is precious in itself, but he stressed more emphasis on the influence of practical interests on our pursuit of truth. Like he said: "the possession of true thoughts means everywhere the possession of invaluable instruments of action; and that our duty to gain truth, so far from being a blank command from out of the blue, or a 'stun' self-imposed by our intellect, can account for itself by excellent practical reasons" (James, 1975a), for example, truth is "a preliminary means towards other vital satisfactions" (James, 1975a). Hence our wanting for truth comes from the difficulty in practice, and in turn the "cash-value" of truth is to make our practice more productive. In this regard, truth is a production of our cooperation with reality. In the progress of cooperation, our interests and the reality interact with each other. At the end of process, the truth is ascertained as a combination of reality or facts and our idea as well as practices. Accompanied with this opinion, truth is not absolutely universal. Because truth does not represent a comprehensive perspective, but shows the fluent cooperation between ideas and reality. In some degree, truth is a kind of 
expression of our subjectivity which contains the attitude and form that we toward to reality. Here, James challenged our stereotype that truth is absolute and completed once for all. Moreover, James argued that, as the tool of helping us dealing with experiences and practices, "truth happens to an idea" (James, 1975a), it is not an inherent quality of one certain idea, but an quality that is justified by the fact that it works well in our practice. In other words, "[truth] becomes true, is made true by events. Its verity is in fact an event, a process: the process namely of its verifying itself, its verification. Its validity is the process of its validation" (James, 1975a). However, it is always necessary for us to keep such an idea in mind that we, as the subject of the verification process, are actively involved in this process. Our productive cooperation with reality justifies the truth of one certain idea. James's description of truth enhances the idea that "human motives sharpen all our questions, human satisfactions lurk in all our answers, all our formulas have a human twist" (James, 1975a), which means that it is impossible to gain the absolute objective truth since our interests are the real prior element of truth. Still, it would be wrong to understand that James's theory of truth is subjective and relative. Instead of resting the objectivity of truth on the place which is independent and above, James stressed the objectivity of truth on the patterns of scientific inquiry. That is to say, "objective truth does not require an absolutist foundation since reliable, yet contingent, patterns of inquiry emerge in the course of experience, patterns that when utilized offer provisionally warranted beliefs" (Uffelman, 2011). Our everlasting testing and verification of truth make it true. In spite of that most of our experiences are allowed to be classified and governed by rules and our induction and classification of experiences is effective, we have to admit that the novelty of experience cannot be ignored. There are always some novel experiences interrogating some fixed truth. Even in some extreme cases, we are forced to modify the old truth or overthrow it utterly. Therefore, all the truths are not final truths, they have to be tested and verified by reality and facts. As long as our life of experience goes on, truth cannot be completed forever.

James's articulation of truth in Pragmatism is rich and detailed, and has greatly challenged the traditional correspondence theory of truth. James proposed an alternative way of understanding truth, namely, a genetic theory of truth. James presents truth as a process in which our relationship with reality is an active and dynamic one, our idea affects and works with reality productively. Thus, truth is not only a noun but also an adjective and an adverb which we used to describe the working process of one certain idea. What is most important in truth is cooperation with reality, but not mirror copy of reality. Here, James provided a unique perspective of understanding truth, which requires us to abandon a completely neutral position but to adopt an active, passionate as well as engaged attitude in the pursuing truth. The real problem is not what is the truth, since "the truth" is not an object that already exists. The problem is rather to explore the nature of those truths which exist in our experiences. What are the 
characteristics of those experiences which we designate by the name of truth. Then we can conclude that truth is not a question of absolute objectivism, but a question of position on which the agreement between idea and reality achieved. One significant implication of this view is that truth is not a logically compelling neutral ground but is a substantive value position, which is exactly an ethical position in general sense. If we proceed in James's way, his statements of moral truth in MPML will be easier to understand. Similarly, the difficulties we encountered in the process of seeking moral truth will change and even disappear.

Now it is time to return to the moral truth. Retrospecting James's analysis of ethical issues in MPML, we can find that the wanting for moral truth gains in prominence when our different demands conflict. We hope the moral truth can become our instrument of dealing with moral conflict and help us handling competing demands. Thus, on this score, we are entitled to say that the main function of moral truth is to make our moral life in harmony, which is consonant with James's claims on truth in Pragmatism. This also intimates that our interpretation on moral truth making reference to his view in pragmatism can hold the water again. Then, at this point, we should ask: what should we understand James's clearest moral ideas-the essence of good is to satisfy demands and the best whole principle? And what does the moral truth like in the Jamesian way? My basic argument advanced here is that, the statements of the essence of good and the best whole principle are two constraints on moral truth, which guides us to seek moral truth. In other words, if final moral truth exists, it is supposed to reflect that the essence of good is to meet the demands and the universe which built on it must be the best one. I hope the following clarification will make my point more convincing.

First of all, it is worth for us to remember that the statements of the essence of good and the best principle were proposed by James under the discussion of casuistic question. Before that, he had shown that moral properties originate from our moral perception and rest upon our subjective support. Therefore, if we examine the source of moral value, as the subject with the equal legitimacy in the world, we shall conclude that everyone's goodness has the same legitimacy. We have no ground to claim that which one's good contains the bigger amount of value, nor can we reduce different goodness to the same universal principle. Or put it bluntly, in James's eyes, moral value is pluralistic. Under such a premise, his expression of the essence of good cannot be understood as a definition of goodness, it just answered the question that what is the common element in all of goods? Indeed, James argues that "the essence of good is simply to satisfy demand" (James, 1979), but this is not to say that he simply equated the satisfaction of demands with the good, which is hotly attacked by many scholars and commentators. What James really wants to express here, in my contention, is that if we examine all the goods in a genetic way, we will find out that the only reason why we describe an action or object being good is that they satisfy someone's demand in a certain way at a certain time and place. If we insist to find a 
common thing among all the goods, the only thing we can get is that the essence of good is to meet the demands. Namely, all the behaviors or objects that we describe as good include the satisfaction of certain demands, but it does not ensure us to say that the satisfied demands are good. Like common sense tells us: some demands can lead to evil. In short, satisfying the demands is a necessary but insufficient condition for being good. One who treats the essence of good as the satisfaction of demands and regards it as a moral truth, ignores the rich content of the good behavior and object in an abstract way and thus leads to the distortion of good. In the same vine, we are not allowed to regard the best whole principle as one completed moral truth but an orientation of our exploration of moral truth. As James had shown, the casuistic question is most tragically practical question. Although every moral value is of identical legitimacy on the ground of origin, not every of them can be realized in the world where we live. "The actually possible in this world is vastly narrower than all that is demanded; and there is always a pinch between the ideal and the actual" (James, 1979). And what is more tragic is that, the gap exists not only because of the limitation of resources, but also because some demands themselves exclude others. Since some demands must be sacrificed, then the victory which philosophically prayed for is the more inclusive one and the best whole principle-the best act is the one that makes for the best whole, in the sense of awakening the least sum of dissatisfaction-shall be the one which is being accepted by the most if not the whole. And the progress of history is an evidence for this: "The course of history is nothing but the story of men's struggles from generation to generation to find the more and more inclusive order. Invent some manner of realizing your own ideals which will also satisfy the alien demands - that and that only is the path of peace!" (James, 1979) Here, James suggests that we have to rethink our relation to this moral principle as an inventive one, in which the truth of the principle is justified by inventing the conditions for its actual realization.

\section{Concluding Remarks}

At this moment, I am allowed to restate my argument with confidence: there is no inconsistency in James's statements of moral truth; conversely, his expression of moral truth exactly shows his overall position on morality. James keeps us exploration of moral truth open, which behind this attitude is a spirit of tolerance. When he says that there is a truth to be ascertained, on the one hand, he hoped to inspire our moral inquiry since "the reasons for the establishment and recognition of a certain truth are always reason for action as guided by truth" (Marchetti, 2010). On the other hand, it shows his promise of morality; he promised that our moral efforts do matter and the moral universe is possible and making in the progress. Similarly, when he said that there is no final truth in ethical realm, this is not a rejection of moral inquiry and moral truth, but indicates that establishing the moral truth is an everlasting enterprise which requires our strenuous attitude and activities. 
James's articulation of moral truth is constructivist and the premise of such constructing is acknowledgement of the pluralism of value and of the possibility of universal consensus about morality, which is another expression of James's idea about the essence of good and the best whole principle. With no doubt, James admits the pluralism in moral value; however, it is wrong for us to declare that he is a value relativist. As he has shown for us, with respect to the origin, all the moral values hold identical legitimacy. But this does not mean that every moral value is equally of significance since they can be measured from other perspectives, which is also encouraged by his pluralism, always seeing another possibility. His acknowledgement of the pluralism of moral value is a kind of respect to subjectivity as well as an acknowledgement of the limitation of human capabilities. As a being with limited reason, we have to admit that, the other is also the subject with the same legitimacy as us; we are not capable of gaining an all-around vision of reality and comparing all the moral values. On the other hand, James holds a strong belief in the possibility of universal consensus about morality. Due to the fact that we use the moral words in the positive sense and our world is not utterly chaotic, it is reasonable for James to hold such a belief. What is more important is that, James believes that this possibility comes from our moral practices rather than logic, as he had shown in the will to believe: our belief and behavior can help in creating realities which is agreed with our idea. Likewise our faith in moral truth can help with the establishment of moral truth by creating the condition of its realization.

Here, James proposed a new way of seeking moral truth. He suggested us to admit that every member of a moral community has their right to be seen and respected, and everyone is supposed to contribute their effort to build a moral universe in which moral truth has been ascertained. He laid special stress on our identity as a participant not a spectator in the process of establishing moral truth. He reminds us that the emotional factors are an intrinsic part of our moral propositions, our preferences and interests, even our physiological structure, environmental structure as well as cultural history, all participate in our moral behaviors and moral judgments. Facing every moral judgment or moral choice, we are taking risks with our whole character. With the belief of moral truth, we justify our moral proposition by our moral practice. James tells us that moral truth should be a mixture, neither pure discovery nor invention. It contains not only rationality but also sensitivity. It is not only a description of facts, but also a prescription of value, with objectivity as well as subjectivity. In short, in James's eyes, moral truth presents a kind of balance which involves all aspects of ourselves and our moral life, which is not only the ultimate and decisive interest in knowledge, but also the interest of emotion, not only the comprehensive proposition of authoritative philosophers, but also requires the joint participation of all of us. James depicts us a picture of moral universe, which is built on moral truth. In the moral universe, although not all values can be realized, all values are respected; in spite of some ideals conflict, the most valuable ideals coexist. All in 
all, James shifted the objectivity, universality and authority of moral truth from the field of theory to the realm of practice. With the faith that moral truth exists, we establish moral truth through the efforts of all of us. However, to be clear, James did not encourage us to trap into the solipsism, believing that we can create anything wanted, he just tried to remind us that thought itself is a most momentous part of fact (James, 1975b), and it always can work with reality productively and beneficially in some way, which implies that our thought of a moral universe and efforts do matter in building a moral world.

\section{Conflicts of Interest}

The author declares no conflicts of interest regarding the publication of this paper.

\section{References}

James. W. (1975a). Pragmatism. A New Name for Some Old Ways of Thinking (pp. 97, 98, 117). Introduction by H. S. Thayer, Cambridge: Harvard University Press.

James. W. (1975b). The Meaning of Truth: A Sequel to Pragmatism (p. 50). Introduction by H. S. Tayer, Cambridge: Harvard University Press.

James. W. (1979). The Will to Believe: And Other Essays in Popular Philosophy (pp. 141, $141,145,151,153,155,161)$. Introduction by E. H. Madden, Cambridge: Harvard University Press.

James. W. (1983). Talks to Teachers on Psychology and to Students on Some of Life's Ideals (p. 132). Introduction by Gerald E. Myers, Cambridge: Harvard University Press.

Marchetti. S. (2010). William James on Truth and Invention in Morality. European Journal of Pragmatism and American Philosophy, 2, 20. https://doi.org/10.4000/ejpap.910

Uffelman, M. (2011). Forging the Self in the Stream of Experience: Classical Currents of Self-Cultivation in James and Dewey. Transactions of the Charles S. Peirce Society, 47, 319-339. https://doi.org/10.2979/trancharpeirsoc.47.3.319 